\title{
Multiple breath washout testing in adults with pulmonary disease and healthy controls - can fewer measurements eventually be more?
}

\author{
Frederik Trinkmann ${ }^{*}$ (D), Johannes Götzmann¹, Daniel Saur ${ }^{1}$, Michele Schroeter ${ }^{1}$, Katharina Roth ${ }^{1}$, Ksenija Stach ${ }^{1,2}$,
} Martin Borggrefe ${ }^{1,2}$, Joachim Saur ${ }^{1}$, Ibrahim Akin ${ }^{1,2}$ and Julia D. Michels ${ }^{1}$

\begin{abstract}
Background: Multiple breath washout (MBW) became a valuable research tool assessing ventilation heterogeneity. However, routine clinical application still faces several challenges. Deriving MBW parameters from three technically acceptable measurements according to current recommendations prolongs test times. We therefore aimed to evaluate reporting only duplicate measurements in healthy adults and pulmonary disease.

Methods: One hundred and fifty-three subjects prospectively underwent conventional lung function testing and closed-circuit SF-MBW. Three technically acceptable MBW-measurements were obtained in 103 subjects.

Results: Lung clearance index (LCl) differed significantly among 19 controls $(7.4 \pm 0.8), 19$ patients with sarcoidosis (8.1 \pm 1.2$), 32$ with bronchial asthma $(9.2 \pm 1.9)$ and 33 with COPD $(10.8 \pm 2.2, p<0.001)$. Within-test repeatability was high (coefficient of variation between $2.5 \%$ in controls and 3.6\% in COPD) and remained unchanged when only including the first two measurements. Likewise, $\mathrm{LCl}$ remained stable with mean absolute changes ranging from $0.9 \pm 0.8 \%$ in controls to $1.5 \pm 0.9 \%$ in COPD $(p=0.1)$. Mean test time reduction differed significantly between groups reaching $200 \mathrm{~s}$ in COPD $(p=0.01)$.
\end{abstract}

Conclusions: Duplicate $\mathrm{SF}_{6}-\mathrm{MBW}$-measurements are sufficient in adult patients with pulmonary disease and healthy controls. $\mathrm{LCl}$ values and intra-test repeatability are not affected reducing total test time statistically significant. Our findings have the potential to further facilitate application of MBW in research and clinical routine.

Trial registration: NCT03176745, June 2, 2017 retrospectively registered.

Keywords: Multiple breath washout, Lung clearance index, Duplicate measurements, Pulmonary disease, Adults

\section{Background}

Multiple breath washout (MBW) testing has been first described in the 1950s [1, 2] for the assessment of ventilation heterogeneity. Clearance of a tracer gas from the lungs is measured most commonly using exogenous sulphur hexafluoride $\left(\mathrm{SF}_{6}\right)$ or endogenous nitrogen $\left(\mathrm{N}_{2}\right)$. In recent years, MBW has become a valuable research

\footnotetext{
*Correspondence: frederik.trinkmann@umm.de

${ }^{1}$ 1st Department of Medicine (Cardiology, Angiology, Pulmonary and Intensive Care), University Medical Centre Mannheim, Medical Faculty Mannheim, Heidelberg University, Theodor-Kutzer-Ufer 1-3, 68167 Mannheim, Germany

Full list of author information is available at the end of the article
}

tool and numerous studies were performed focusing on paediatric populations and patients with cystic fibrosis or bronchiectasis [3-5]. Little data is available for adults although promising results for diagnosis and prediction of chronic obstructive pulmonary disease (COPD) became available recently [6-8]. Nevertheless, several challenges exist and still prevent MBW from routine clinical application. Open wash-in $\mathrm{SF}_{6}$-MBW using a mass spectrometer is considered to be the gold standard [9] while being associated with high costs and effort and not holding regulatory approval. As a consequence, indirect techniques such as $\mathrm{N}_{2}-\mathrm{MBW}$ have been experiencing a renaissance. Pure oxygen is used for $\mathrm{N}_{2}$ wash-out while 
directly measuring oxygen and carbon dioxide concentrations. Considerable inaccuracies can therefore be introduced due to measurement errors in respiratory gas concentrations, $\mathrm{N}_{2}$ back diffusion and changes in breathing pattern caused by $100 \%$ oxygen $[10,11]$. In contrast, $\mathrm{SF}_{6}$ concentrations can be directly measured with high accuracy using a newly developed photo-magnetoacoustic multi-gas analyser $[12,13]$. This allowed the construction of a portable device for $\mathrm{SF}_{6}-\mathrm{MBW}$ [14] with considerably lower gas concentrations as compared to mass spectrometry using $4 \% \mathrm{SF}_{6}[11,15]$ and is associated with significant cost reduction while environmental effects and maintenance become negligible. Moreover, the system has regulatory approval by the U.S. Food and Drug Administration and CE marking allowing its use in clinical routine.

Recently, publication of an ERS/ATS consensus statement was an important step to standardization of the technique in general [9]. Reporting MBW parameters from three technically acceptable measurements is recommended independently of the test gas used. However, this can lead to prolonged duration in $\mathrm{N}_{2}-\mathrm{MBW}$ where wash-out is time critical while in $\mathrm{SF}_{6}-\mathrm{MBW}$ wash-in and costs are relevant factors. For both tracer gases, several adaptions to the measurement protocols have been proposed including reduction of total measurements or earlier cut-offs for terminating wash-out [16-19]. Moreover, a closed circuit setup for $\mathrm{SF}_{6}-\mathrm{MBW}$ was shown to effectively reduce wash-in times further facilitating application [20]. Therefore, the aims of our study were to prospectively evaluate (1) the feasibility of closed-circuit $\mathrm{SF}_{6}-\mathrm{MBW}$ in healthy adults and in pulmonary disease, (2) the influence of reporting duplicate measurements on lung clearance index (LCI), with-in test repeatability and total test time.

\section{Methods \\ Subjects}

The total collective consisted of 153 subjects including pulmonary healthy controls $(n=24)$ as well as patients suffering from COPD $(n=50)$, bronchial asthma $(n=54)$ and sarcoidosis $(n=25)$. All participants were in clinically stable condition and written informed consent was obtained prior to inclusion. The study protocol was approved by our local ethics committee and registered at clinicaltrials.gov (NCT03176745). Controls had normal lung function testing including whole-body plethysmography and transfer factor, no previously diagnosed pulmonary disease as well as no respiratory symptoms. Lung function testing including the shapes of flow-volume and flow-pressure curves was independently assessed by two experienced investigators. Detailed information on classification criteria of controls and pulmonary disease is given in the Additional file 1. Patients in unstable clinical condition, with infective lung disease or need for long term oxygen therapy were not included.

\section{Study protocol}

All subjects underwent three consecutive MBW tests in upright position followed by whole-body plethysmography (MasterScreen Body, CareFusion 234 GmbH, Höchberg, Germany). Functional residual capacity (FRC) was determined from end-expiratory shutter manoeuvres during normal breathing. If obstruction was present $\left(\mathrm{FEV}_{1} /\right.$ vital capacity $<80 \%$ of predicted), we performed reversibility testing in patients with COPD (88\%), bronchial asthma (66\%), or sarcoidosis (37\%), respectively. Doses of $40 \mu \mathrm{g}$ ipratropium bromide and $100 \mu \mathrm{g}$ fenoterol hydrobromide were administered using a soft-mist haler (Berodual Respimat, Boehringer Ingelheim Pharma $\mathrm{GmbH} \& \mathrm{Co}$. KG, Germany). Transfer factor (TLCO) was determined in single breath technique in all subjects.

\section{Multiple breath washout}

For MBW testing, we used a commercially available device (Innocor, PulmoTrace ApS, Glamsbjerg, Denmark). The closed-circuit system consists of a 3-1 rebreathing bag filled with a mixture of room air and test gas $(94 \%$ $\mathrm{O}_{2}, 1 \% \mathrm{SF}_{6}$ and $5 \% \mathrm{~N}_{2} \mathrm{O}$, PulmoTrace ApS) from an onboard gas cylinder as previously described in detail [20]. FRC and LCI were derived from three consecutive washouts using proprietary software provided by the manufacturer (software version 8.0 beta 1). Subjects were breathing tidally and the test was stopped when end tidal $\mathrm{SF}_{6}$ had fallen to less than 1/40th of the starting concentration. Only patients with three technically acceptable measurements based on slightly modified ATS/ERS criteria were included in final analysis (Additional file 1).

\section{Statistical analysis}

Data was analysed using MedCalc version 17.4 (MedCalc Software, Mariakerke, Belgium). Mean values are given \pm SD unless stated otherwise. Differences between disease entities were assessed by ANOVA for continuous variables or Chi-squared test for categorical variables. Student's t-test was used to evaluate differences between patients with successful and unsuccessful measurements as well as duplicate and triplicate measurements, respectively. For the duplicate measurement approach, mean LCI values were derived from the first two runs. The coefficient of variation $(\mathrm{CV})$ was calculated as $\mathrm{SD} /$ mean from duplicate and triplicate $\mathrm{MBW}$ measurements. Mean percentage changes in LCI are given as absolute values (modulus) to facilitate comparison with CV. A planned subgroup sample size of 20 would provide $80 \%$ power for detecting a difference of $1 \pm 1.5 \%$ in LCI. An alpha error of less than 5\% in two-sided testing was considered statistically significant. 


\section{Results}

A total of 103 subjects were included in the final analysis. Baseline characteristics and lung function data are given in Table 1 . Mean LCI differed significantly between controls $(7.4 \pm 0.8)$, sarcoidosis $(8.1 \pm 1.2)$, bronchial asthma (9.2 \pm 1.9$)$ and COPD $(10.8 \pm 2.2, p<0.001$, ANOVA). Within-test repeatability was high with an overall $\mathrm{CV}$ of $3.1 \%$, ranging from $2.5 \%$ in controls to $3.6 \%$ in COPD (Table 2). FRC as determined by plethysmography yielded significantly higher values as compared to MBW in patients with COPD (3.8 \pm 0.9 vs. $3.0 \pm 0.8 \mathrm{p}<0.001)$ and asthma $(2.9 \pm 0.8$ vs. $2.4 \pm 0.7$, $p<0.05)$. In contrast, no differences were found in controls $(3.2 \pm 0.5$ vs. $3.0 \pm 0.6, p=0.1)$ or sarcoidosis $(3.1 \pm 0.7$ vs. $2.9 \pm 0.7, p=0.4)$.

When only including the first two MBW measurements, LCI remained stable in all groups with mean absolute changes (modulus) of $0.9 \pm 0.8 \%$ in controls, $1.5 \pm 0.9 \%$ in COPD, $1.1 \pm 0.8 \%$ in sarcoidosis and $1.3 \pm$ $0.7 \%$ in asthma, respectively ( $\mathrm{p}=0.1$, ANOVA, Fig. 1). Within-test repeatability was not negatively affected when only including two instead of three MBW measurements. Overall CV significantly decreased from 3.1 to $2.9 \%$ ( $\mathrm{p}<0.05$, $\mathrm{t}$-test). Total test times differed significantly in all groups when comparing the duplicate to triplicate measurement approach (Table 2). Mean test time reductions ranged from $155 \mathrm{~s}$ in controls to $200 \mathrm{~s}$ in COPD ( $p=0.01$, ANOVA, Fig. 2) lying within the variation of an individual test in the respective group.

We had to exclude datasets from 50 subjects representing $33 \%$ of the screened collective due to at least one invalid measurement. A minimum of two technically acceptable MBW measurements could be obtained in $92 \%$ of COPD, in $93 \%$ of bronchial asthma, in all sarcoidosis patients as well as in all healthy controls from the complete cohort (Fig. 3). There was no difference in the number of successful measurements between groups ( $p=0.3$, Chi-squared test). In patients with at least two successful measurements $(n=145)$, an average $84 \%$ of valid trials were obtained from the first two out of three (Additional file 1: Figure S1). To further assess factors associated with an unsuccessful MBW test, we analysed baseline and lung function data of the complete collective screened. Subjects with unsuccessful measurements had significantly higher TLC $(112 \pm 19$ vs. $105 \pm 16 \%$ of predicted) and RV (142 \pm 43 vs. $129 \pm 28 \%$ of predicted, $p<0.05$ each, t-test) as compared to subjects with complete data sets. Moreover, excluded patients were more frequently current smokers (50 vs. $17 \%, p<0.05$, Chi-squared test) with details given in (Additional file 1: Table S1).

Table 1 Baseline characteristics and lung function data (analysed collective, $n=103$ )

\begin{tabular}{|c|c|c|c|c|c|c|c|c|c|c|}
\hline & & Control $(n=$ & & $\operatorname{COPD}(n=3$ & & Asthma $(n=$ & & Sarcoidosis & =19) & \\
\hline & Unit & Mean \pm SD & Range & Mean \pm SD & Range & Mean \pm SD & Range & Mean \pm SD & Range & $p$-value \\
\hline Age & years & $56 \pm 22$ & $21-85$ & $66 \pm 10$ & $46-86$ & $59 \pm 16$ & $27-88$ & $51 \pm 10$ & $37-79$ & $<0.01$ \\
\hline Height & $\mathrm{cm}$ & $172 \pm 10$ & $157-198$ & $168 \pm 6$ & $157-182$ & $166 \pm 10$ & $145-188$ & $174 \pm 8$ & $150-187$ & $<0.05$ \\
\hline Weight & $\mathrm{kg}$ & $80 \pm 21$ & $50-132$ & $81 \pm 14$ & $50-120$ & $80 \pm 17$ & $45-117$ & $76 \pm 19$ & $47-128$ & 0.8 \\
\hline BMI & $\mathrm{kg} / \mathrm{m}^{2}$ & $27.1 \pm 7.6$ & $17.5-49.1$ & $28.8 \pm 4.9$ & $20.3-42.5$ & $28.8 \pm 6.2$ & $16.1-44.5$ & $25.6 \pm 7.2$ & $13.4-46.5$ & 0.3 \\
\hline Smoker & & & & & & & & & & \\
\hline Never & n (\%) & $15(79)$ & & 1 (3) & & $14(44)$ & & $12(63)$ & & $<0.001$ \\
\hline Current & n (\%) & $2(11)$ & & $8(24)$ & & $6(19)$ & & $1(5)$ & & \\
\hline Former & n (\%) & $2(11)$ & & $24(73)$ & & $12(38)$ & & $6(32)$ & & \\
\hline$R T$ & n (\%) & - & & $29(88)$ & & $21(66)$ & & $7(37)$ & & 0.8 \\
\hline Positive & n (\%) & - & & $8(28)$ & & $6(29)$ & & $1(14)$ & & \\
\hline $\mathrm{FEV}_{1} \mathrm{NC}$ & $\%$ pred & $98 \pm 8$ & $84-114$ & $73 \pm 17$ & $42-103$ & $89 \pm 11$ & $58-110$ & $92 \pm 11$ & $70-110$ & $<0.001$ \\
\hline $\mathrm{FEV}_{1}$ & $\%$ pred & $96 \pm 14$ & $65-127$ & $65 \pm 20$ & $36-106$ & $86 \pm 18$ & $38-110$ & $89 \pm 16$ & $57-112$ & $<0.001$ \\
\hline TLC & $\%$ pred & $103 \pm 10$ & $87-116$ & $110 \pm 19$ & $72-148$ & $105 \pm 17$ & $65-141$ & $100 \pm 15$ & $83-139$ & 0.2 \\
\hline VC & $\%$ pred & $96 \pm 16$ & $64-119$ & $91 \pm 23$ & $41-142$ & $98 \pm 21$ & $59-136$ & $96 \pm 16$ & $67-135$ & 0.5 \\
\hline RV & $\%$ pred & $122 \pm 21$ & $82-177$ & $147 \pm 33$ & $108-211$ & $123 \pm 19$ & $81-156$ & $112 \pm 22$ & $69-158$ & $<0.001$ \\
\hline $\mathrm{RV} / \mathrm{TLC}$ & $\%$ pred & $113 \pm 17$ & $86-152$ & $129 \pm 19$ & $100-184$ & $115 \pm 14$ & $91-151$ & $105 \pm 13$ & $75-123$ & $<0.001$ \\
\hline TLCONA & $\%$ pred & $99 \pm 9$ & $88-114$ & $63 \pm 18$ & $28-95$ & $83 \pm 13$ & $62-112$ & $85 \pm 16$ & $44-122$ & $<0.001$ \\
\hline$F R C_{\text {pleth }}$ & I & $3.2 \pm 0.5$ & $2.4-4.0$ & $3.8 \pm 0.9$ & $2.1-5.8$ & $2.9 \pm 0.8$ & $1.7-4.8$ & $3.1 \pm 0.7$ & $1.6-4.2$ & $<0.001$ \\
\hline
\end{tabular}

$B M I$ body mass index, $R T$ reversibility testing, $F E V_{1}$ forced expiratory volume in $1 \mathrm{~s}, V C$ vital capacity, $T L C$ total lung capacity, $R V$ residual volume, $T L C O$ transfer factor for carbon monoxide corrected for alveolar volume, $F R C_{\text {pleth }}$ functional residual capacity in plethysmography, $\%$ pred percent of predicted, $S D$ standard deviation

\# $p$-values between groups were calculated using ANOVA for continuous variables or Chi-squared test for categorical variables, respectively 
Table 2 Multiple breath washout data $(n=103)$

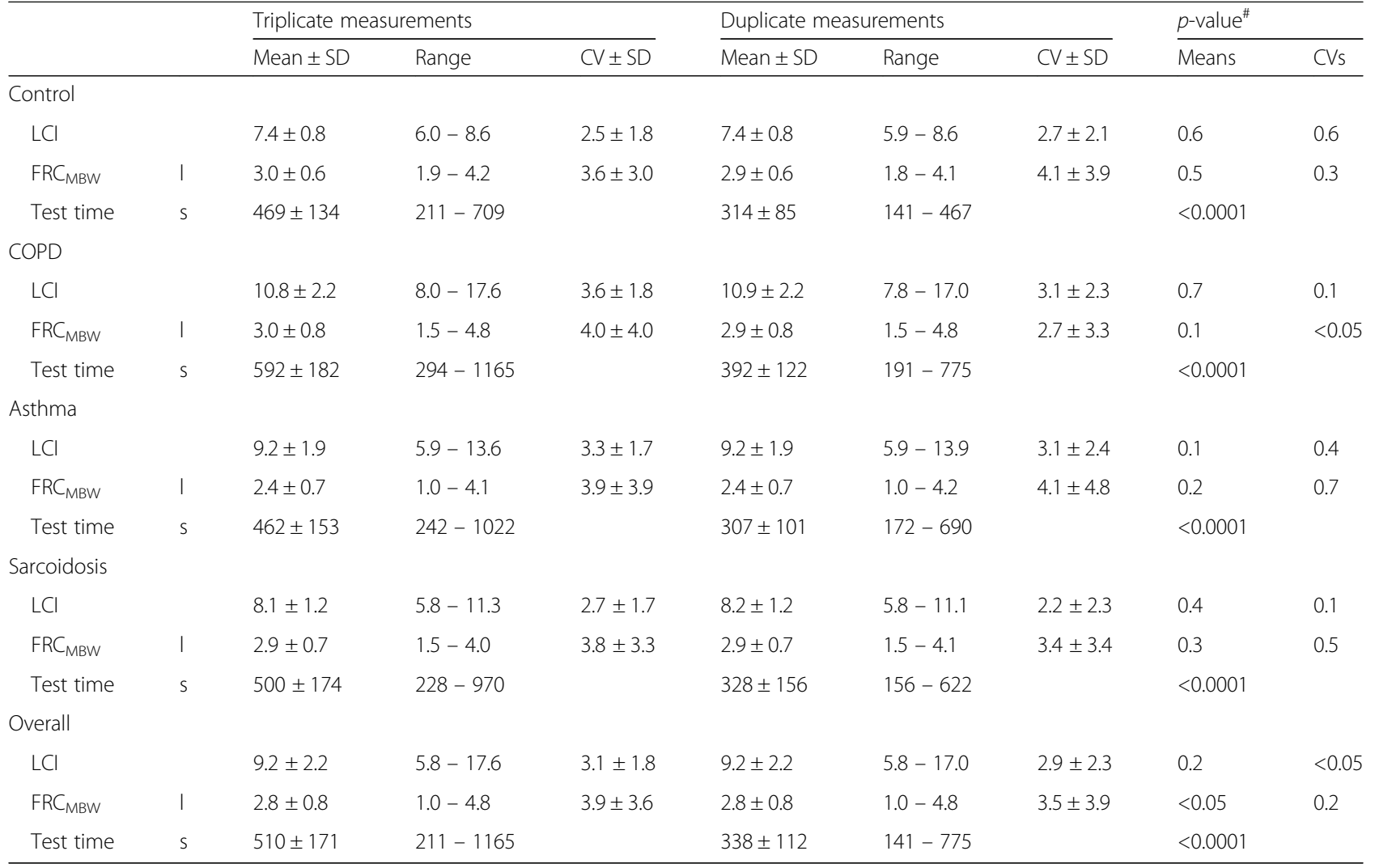

$L C l$ lung clearance index, $F R C_{M B W}$ functional residual capacity in multiple breath washout, $S D$ standard deviation, $C V$ coefficient of variation [\%], $C I$ 95\%-confidence interval \# $p$-values between means of measurement groups were calculated using paired Student's t-test

\section{Discussion}

We were able to demonstrate that determination of LCI derived from $\mathrm{SF}_{6}-\mathrm{MBW}$ is feasible in adults with pulmonary disease and healthy controls. Values are not altered when only reporting two instead of three technically acceptable measurements. Mean changes were considerably lower than within-test repeatability in all groups and overall test times could be noticeably reduced. LCI differed among all groups and yielded the highest readings in COPD.

Until now, data for comparison of diseases other than cystic fibrosis or bronchiectasis is scarce for our $\mathrm{SF}_{6}$ based setup. The feasibility of $\mathrm{N}_{2}-\mathrm{MBW}$ in patients with COPD was recently evaluated by Fähndrich and coworkers. An increasing ventilation heterogeneity in patients with airway obstruction or hyperinflation was

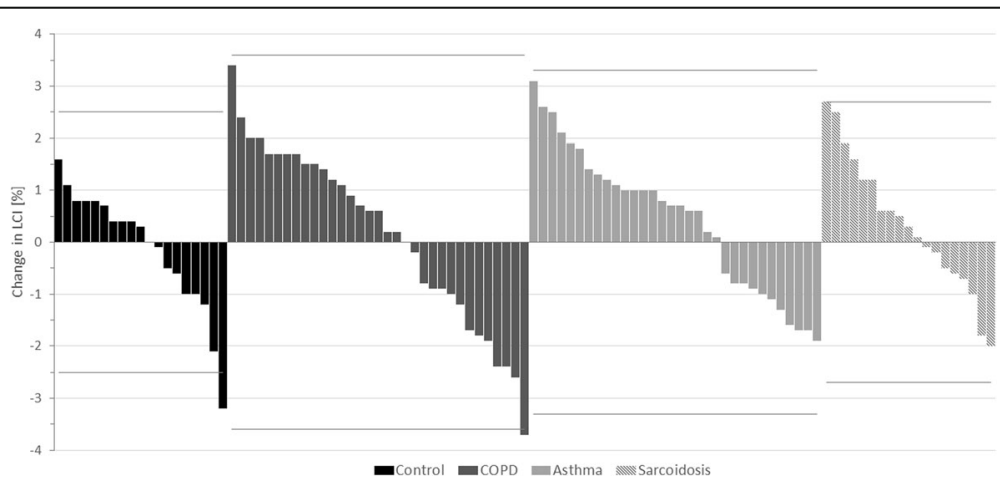

Fig. 1 Change in lung clearance index $(\mathrm{LCl})$. Waterfall diagram of the $\mathrm{LCl}$ percentage change when comparing duplicate and triplicate measurements $(n=103)$. No differences in mean absolute changes (modulus) were found between controls $(0.9 \pm 0.8 \%)$, COPD $(1.5 \pm 0.9 \%)$, sarcoidosis $(1.1 \pm 0.8 \%)$ and asthma $(1.3 \pm 0.7 \%)$ in ANOVA $(p=0.1)$. Solid grey lines indicate mean coefficient of variation $(C V)$ of the respective group with only two datasets marginally exceeding within-test repeatability 


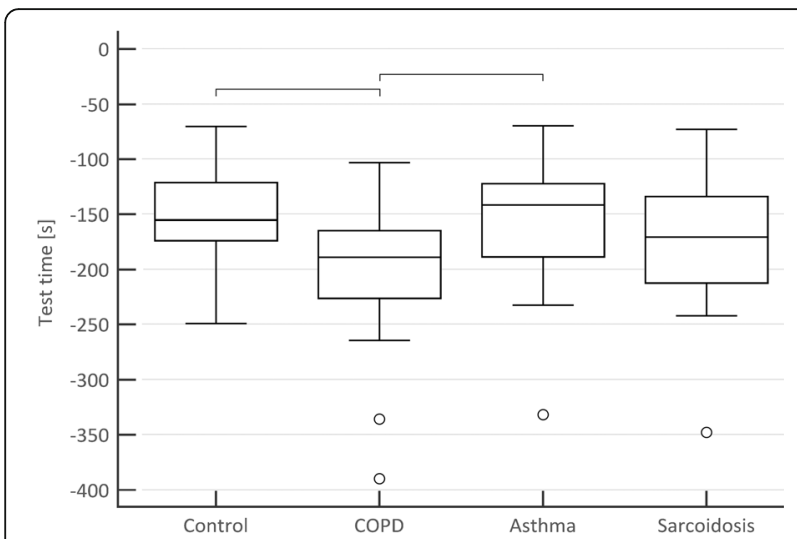

Fig. 2 Test time reduction. Absolute test time reductions for duplicate as compared to triplicate measurements $(n=103)$. Means ranging from $155 \pm 49 \mathrm{~s}$ in controls to $200 \pm 62 \mathrm{~s}$ in COPD. Connectors indicate statistically significant differences ( $p=0.01$, ANOVA)

found with a mean LCI of 12.6 as compared to 7.0 in healthy controls [8]. However, it has been demonstrated that $\mathrm{N}_{2}-\mathrm{MBW}$ reproducibly yields higher absolute LCI readings than $\mathrm{SF}_{6}-\mathrm{MBW}[21,22]$. Much of this difference can be potentially explained by differing physiological properties and the aforementioned technical aspects associated with the test gases [11, 21, 23]. $\mathrm{N}_{2}$ has a higher diffusion rate and smaller molar mass as compared to $\mathrm{SF}_{6}$ resulting in a more proximal diffusionconvection front [9]. Moreover, $\mathrm{SF}_{6}$ may not reach very poorly ventilated regions during wash-in while endogenous $\mathrm{N}_{2}$ may prolong wash-out from these regions resulting in higher LCI values. $\mathrm{N}_{2}$ back diffusion plays an important role becoming most pronounced at the end of the wash-out where it may contribute $20 \%$ of the measured signal [23] and increases with longer wash-out times [24]. Recent findings convincingly support this explanation as $\mathrm{N}_{2}$-excretion was demonstrated to increase with cardiac output under exercise conditions

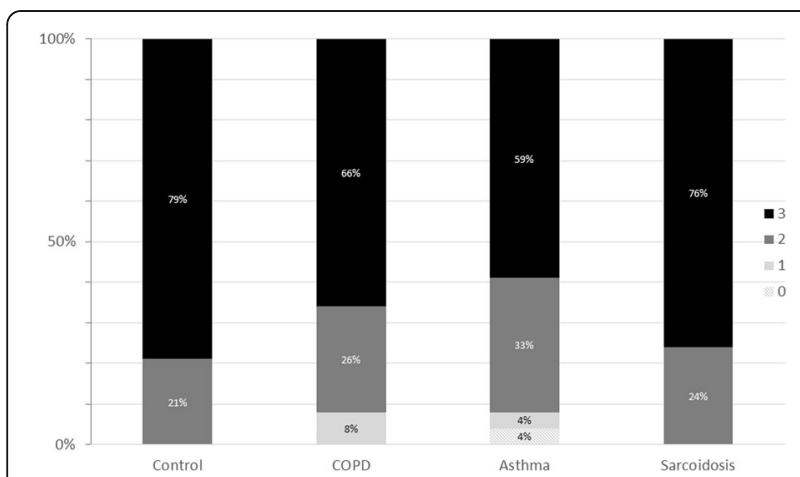

Fig. 3 Successful measurements. No difference in the number of successful measurements was found between controls, COPD, asthma, or sarcoidosis ( $p=0.3$, Chi-squared test) in the overall collective $(n=153)$ simultaneously measuring both tracer gases [10]. Previously, excretion rates were found to fit a multiphase exponential curve although varying intra- and inter-individually. Application of correction equations has shown to significantly reduce the effect of tissue $\mathrm{N}_{2}$, however, it cannot be eliminated completely. While also not affecting the interpretation of treatment effects, application of tissue $\mathrm{N}_{2}$ correction equations is therefore currently not recommended [24]. As a consequence, values acquired with either technique should not be used interchangeably complicating direct comparison of studies using different tracer gases.

In controls, we found good agreement for FRC as determined by body plethysmography and MBW, respectively. This is in accordance with previous in-vitro validation studies using the open-circuit approach $[12,13]$. Only ventilated areas will contribute to FRC determination using MBW whereas compressible gas volumes are measured in body plethysmography [22]. This relates to significant differences in FRC between the two techniques seen in patients with obstructive ventilation disorders in our collective. In general, deriving FRC from panting manoeuvres yields accurate results in controls as well as milder obstructive disease when controlling panting frequency $[25,26]$. With increasing disease severity, body plethysmography was shown to systematically overestimate lung volume as compared to both computed tomography and Helium dilution [27]. However, there is no consent about the ideal technique for measuring lung volumes. Our measurement setup allows determination of FRC from end-expiratory shutter manoeuvres during normal breathing. This overcomes important impediments to the panting-based approach such as incomplete equilibration of mouth and alveolar pressures and does not lead to additional hyperinflation or increase in end-expiratory pressures. Computed tomography may be affected by postural lung volume changes [28] and incomplete inspiration while Helium dilution may result in underestimation due to gas trapping [29]. Interestingly, gas trapping independently predicts patients with a larger difference of plethysmography and computed tomography derived total lung capacity [30] and inter-modal differences even were postulated as a diagnostic tool differentiating COPD severity [31].

Within-test repeatability found in our study is comparable to previously published data in stable adults showing CVs between 3.2 and $4.5 \%$ using $\mathrm{SF}_{6}$ as tracer gas $[4,20,32]$. Closed-circuit tracer gas wash-in has been demonstrated to reduce wash-in times by 32 to $50 \%$ in cystic fibrosis patients and healthy controls [20] as compared to the conventional open-circuit technique. We could achieve another 34\% reduction of total test time when only reporting two technically acceptable measurements. Therefore, a complete dataset allowing 
calculation of LCI can be acquired in less than $7 \mathrm{~min}$ on the average even in patients with COPD using $\mathrm{SF}_{6}$. In contrast, $\mathrm{N}_{2}$ based measurements are usually more time consuming and wash-out times increase with disease severity in cystic fibrosis [33]. In patients with severe COPD, durations of up to $20 \mathrm{~min}$ have been reported for a single measurement leading to a low rate of successful measurements of 55\% [8]. Although mean test time reductions due to omitting a third measurement should not be overemphasized in our collective, time savings can add up to over $6 \mathrm{~min}$ in an individual patient. Mean overall rejection rate was $33 \%$ which is comparable to a previous report by Jensen where $27 \%$ of $\mathrm{N}_{2}$-MBW measurements were excluded after a standardized review process [34]. In our collective, patients suffering from obstructive ventilation disorders such as COPD and bronchial asthma showed the highest rates of 34 and $41 \%$, respectively. Patients with unsuccessful measurements had higher TLC and RV values corresponding to hyperinflation. In both obstructive disorders, the majority of valid tests were obtained from the first two runs. Notably, in the trial by Jensen up to seven measurements were performed until the operator determined that three good trials were obtained or the subject was unable to continue testing. In contrast, we did not repeat invalid tests in our protocol calculating success rates from a set of three consecutive MBW measurements.

When applying adult quality control criteria to a paediatric population, within-test repeatability could be significantly reduced from 8.5 to $4.7 \%$ using $\mathrm{SF}_{6}$. However, success rates were as low as $41 \%$ beyond infancy and could be increased to an overall $70 \%$ using preschool recommendations [17]. In our collective, two valid measurements were obtained from the first two runs in an average 4 out of 5 patients. The smallest benefit of an additional third measurement was seen in patients with COPD where $96 \%$ of successful trials were acquired from the first two runs. In context of the lower overall success rates in patients with airway obstruction, this is an important finding and reducing time and effort needed is crucial for clinical application of MBW. Moreover, it has been hypothesized that inclusion of poorly ventilated lung regions not reached during the initial but subsequent trials could potentially increase LCI values. This effect should become more pronounced in severe obstructive disease [8]. Percentage changes were distributed quite homogenously in our collective including increases as well as decreases when comparing duplicate versus triplicate LCI measurements. This is in accordance with previous findings where LCI and FRC values remained unchanged in patients with cystic fibrosis [17].

When interpreting our results, several points should be taken into consideration. Although we included a broad spectrum of pulmonary disorders, interstitial lung disease is underrepresented being restricted to patients with sarcoidosis. While lung disease affecting lung parenchyma may not necessarily increase ventilation heterogeneity, MBW testing could be potentially beneficial in disease entities affecting peripheral airway function. These may include respiratory bronchiolitis-associated interstitial lung disease (RB-ILD) or cryptogenic organizing pneumonia (COP). Our investigation focuses on LCI as the predominant MBW parameter reported in the literature. Therefore, our findings should not be uncritically transferred to other indices such as phase III analyses or moment ratios. Considerably larger $\mathrm{CV}$ s have been shown for parameters of conductive $\left(\mathrm{S}_{\text {cond }}\right)$ and acinar $\left(S_{\text {acin }}\right)$ ventilation heterogeneity [7]. At the same time, lower success rates are postulated as a result of the more elaborate underlying algorithm. Due to the crosssectional design, we are not able to provide estimates of the minimal clinical important difference for $\mathrm{SF}_{6}-\mathrm{MBW}$. From technical considerations, it should be possible to detect small longitudinal changes due to the high intratest repeatability while further research is required. Nevertheless, our findings add important information to the scarce data available on adult MBW testing. For the first time, we could demonstrate the feasibility of $\mathrm{SF}_{6^{-}}$ MBW in a variety of pulmonary disorders in a large adult collective. Moreover, we included a wide range of LCI values and age classes meeting the requirements of both research and clinical applications.

\section{Conclusions}

We were able to demonstrate that duplicate LCI measurements derived from $\mathrm{SF}_{6}-\mathrm{MBW}$ are sufficient in adult patients with COPD, bronchial asthma, sarcoidosis as well as in healthy controls. LCI values and intra-test repeatability are not affected while total test time is reduced statistically significant. Our findings have the potential to further facilitate application of MBW testing in research and daily clinical routine.

\section{Additional file}

Additional file 1: Classification criteria. Acceptability criteria for MBW. Table S1. Analysis of excluded subjects. Figure S1. Success rates for the first two out of three trials in patients with at least two successful measurements. (DOCX $194 \mathrm{~kb}$ )

\footnotetext{
Abbreviations

COP: Cryptogenic organizing pneumonia; COPD: Chronic obstructive pulmonary disease; CV: Coefficient of variation; FRC: Functional residual capacity; LCl: Lung clearance index; MBW: Multiple breath washout; $\mathrm{N}_{2}$ : Nitrogen; RB-ILD: Respiratory bronchiolitis-associated interstitial lung disease; RV: Residual volume; $\mathrm{S}_{\text {acin }}$ : Acinar ventilation heterogeneity; $\mathrm{S}_{\text {cond: }}$ Conductive ventilation heterogeneity; $\mathrm{SF}_{6}$ : Sulphur hexafluoride; TLC: Total lung capacity; TLCO: Transfer factor
} 


\section{Acknowledgements}

We thank all patients who agreed to take part in the study, as well as our technical assistants Maria Moritz and Sabrina Krämer (1st Department of Medicine, University Medical Centre Mannheim) for their help in acquiring lung function data.

\section{Funding}

We are very grateful for receiving financial support from Ms. Ester Knorr (Germany, private donation), Markedsmodningsfonden (Denmark, public grant), Heidelberg University (MEAMEDMA, internal grant), as well as the funding programme Open Access Publishing by Deutsche Forschungsgemeinschaft (DFG) and Heidelberg University.

\section{Availability of data and materials}

All data generated or analysed during this study are included in this published article.

\section{Prior publication}

An abstract containing preliminary analyses of the underlying data was presented at the 2017 annual congress of the European Respiratory Society (OA496) in Milan, Italy.

\section{Authors' contributions}

All authors have read and approved the manuscript. FT writing first draft of manuscript, study design, data management, data analysis, JG data collection, data management, data analysis, DS data collection, data management, MS data collection, data management, KR data collection, data management, KS data management, data analysis, MB study design, revision of manuscript, JS study design, data analysis, revision of manuscript, IA study design, revision of manuscript, JDM study design, data analysis, revision of manuscript.

\section{Ethics approval and consent to participate}

The study protocol was approved by Medical Ethics Committee II (Medical Faculty Mannheim, Heidelberg University, Germany) and informed consent was obtained from all participants.

\section{Consent for publication}

Does not apply.

\section{Competing interests}

The authors declare that they have no competing interests.

\section{Publisher's Note}

Springer Nature remains neutral with regard to jurisdictional claims in published maps and institutional affiliations.

\section{Author details}

1'1st Department of Medicine (Cardiology, Angiology, Pulmonary and Intensive Care), University Medical Centre Mannheim, Medical Faculty Mannheim, Heidelberg University, Theodor-Kutzer-Ufer 1-3, 68167 Mannheim, Germany. ${ }^{2}$ DZHK (German Centre for Cardiovascular Research), partner site Mannheim, University Medical Centre Mannheim, Medical Faculty Mannheim, Heidelberg University, Theodor-Kutzer-Ufer 1-3, 68167 Mannheim, Germany.

Received: 20 July 2017 Accepted: 29 November 2017

Published online: 11 December 2017

\section{References}

1. Becklake MR. A new index of the intrapulmonary mixture of inspired air. Thorax. 1952;7(1):111-6.

2. Robertson JS, Siri WE, Jones HB. Lung ventilation patterns determined by analysis of nitrogen elimination rates; use of mass spectrometer as a continuous gas analyzer. J Clin Invest. 1950;29(5):577-90.

3. Aurora P, Gustafsson P, Bush A, Lindblad A, Oliver C, Wallis CE, Stocks J. Multiple breath inert gas washout as a measure of ventilation distribution in children with cystic fibrosis. Thorax. 2004;59(12):1068-73.

4. Horsley AR, Gustafsson PM, Macleod KA, Saunders C, Greening AP, Porteous DJ, Davies JC, Cunningham S, Alton EW, Innes JA. Lung clearance index is a sensitive, repeatable and practical measure of airways disease in adults with cystic fibrosis. Thorax. 2008;63(2):135-40.
5. Gonem S, Scadding A, Soares M, Singapuri A, Gustafsson P, Ohri C, Range S, Brightling CE, Pavord I, Horsley A, Siddiqui S. Lung clearance index in adults with non-cystic fibrosis bronchiectasis. Respir Res. 2014;15:59.

6. Zaigham S, Wollmer P, Engstrom G. The Association of Lung Clearance Index with COPD and FEV1 Reduction in 'Men Born in 1914'. COPD. 2017; 14(3):324-9. doi:10.1080/15412555.2017.1314455. Epub 2017 Apr 28.

7. Husemann K, Berg N, Engel J, Port J, Joppek C, Tao Z, Singer F, Schulz H, Kohlhaufl M. Double tracer gas single-breath washout: reproducibility in healthy subjects and COPD. Eur Respir J. 2014;44(5):1210-22.

8. Fähndrich S, Lepper P, Trudzinski F, Seibert M, Wagenpfeil S, Bals R. Lung clearance index is increased in patients with COPD - LCl measurements in the daily routine. J Pulm Respir Med. 2016;6(3):354.

9. Robinson PD, Latzin P, Verbanck S, Hall GL, Horsley A, Gappa M, Thamrin C, Arets HG, Aurora P, Fuchs SI, et al. Consensus statement for inert gas washout measurement using multiple- and single- breath tests. Eur Respir J. 2013;41(3):507-22.

10. Sullivan L, Forno E, Pedersen K, Nielsen JG, Weiner DJ. Nitrogen backdiffusion during multiple-breath washout with 100\% oxygen. Eur Respir J. 2017;50(3). doi:10.1183/13993003.00679-2017. Print 2017 Sep.

11. Nielsen JG. Lung clearance index: should we really go back to nitrogen washout? Eur Respir J. 2014;43(2):655-6.

12. Gonem S, Singer F, Corkill S, Singapuri A, Siddiqui S, Gustafsson P. Validation of a photoacoustic gas analyser for the measurement of functional residual capacity using multiple-breath inert gas washout. Respiration. 2014;87(6):462-8.

13. Horsley A, Macleod K, Gupta R, Goddard N, Bell N. Enhanced photoacoustic gas analyser response time and impact on accuracy at fast ventilation rates during multiple breath washout. PLoS One. 2014;9(6):e98487.

14. Clemensen P, Christensen P, Norsk P, Gronlund J. A modified photo- and magnetoacoustic multigas analyzer applied in gas exchange measurements. J Appl Physiol (1985). 1994;76(6):2832-9.

15. Subbarao P, Milla CE, Morgan WJ, Ratjen F, Workshop AG. Corrections to an ATS workshop report on multiple-breath washout testing for patients with cystic fibrosis. Ann Am Thorac Soc. 2017;14(1):145.

16. Yammine S, Singer F, Abbas C, Roos M, Latzin P. Multiple-breath washout measurements can be significantly shortened in children. Thorax. 2013;68(6):586-7.

17. Robinson PD, Stocks J, Aurora P, Lum S. Abbreviated multi-breath washout for calculation of lung clearance index. Pediatr Pulmonol. 2013;48(4):336-43

18. Gronbaek J, Hallas HW, Arianto L, Pedersen K, Thomsen A, Chawes BL, Bisgaard H. New time-saving predictor algorithm for multiple breath washout in adolescents. Pediatr Res. 2016;80(1):49-53.

19. Hannon D, Bradley JM, Bradbury I, Bell N, Elborn JS, O'Neill K. Shortened lung clearance index is a repeatable and sensitive test in children and adults with cystic fibrosis. BMJ Open Respir Res. 2014;1(1):e000031.

20. Horsley AR, O'Neill K, Downey DG, Elborn JS, Bell NJ, Smith J, Owers-Bradley J. Closed circuit rebreathing to achieve inert gas wash-in for multiple breath wash-out. ERJ Open Res. 2016;2(1). eCollection 2016 Jan.

21. Yammine S, Lenherr N, Nyilas S, Singer F, Latzin P. Using the same cut-off for sulfur hexafluoride and nitrogen multiple-breath washout may not be appropriate. J Appl Physiol (1985). 2015;119(12):1510-2.

22. Jensen R, Stanojevic S, Gibney K, Salazar JG, Gustafsson P, Subbarao P, Ratjen $F$. Multiple breath nitrogen washout: a feasible alternative to mass spectrometry. PLoS One. 2013;8(2):e56868.

23. Nielsen N, Nielsen JG, Horsley AR. Evaluation of the impact of alveolar nitrogen excretion on indices derived from multiple breath nitrogen washout. PLoS One. 2013;8(9):e73335.

24. Kane M, Rayment JH, Jensen R, McDonald R, Stanojevic S, Ratjen F. Correcting for tissue nitrogen excretion in multiple breath washout measurements. PLoS One. 2017;12(10):e0185553.

25. Rodenstein DO, Stanescu DC. Frequency dependence of plethysmographic volume in healthy and asthmatic subjects. J Appl Physiol Respir Environ Exerc Physiol. 1983;54(1):159-65.

26. Shore SA, Huk O, Mannix S, Martin JG. Effect of panting frequency on the plethysmographic determination of thoracic gas volume in chronic obstructive pulmonary disease. Am Rev Respir Dis. 1983;128(1):54-9.

27. O'Donnell CR, Bankier AA, Stiebellehner L, Reilly JJ, Brown R, Loring SH. Comparison of plethysmographic and helium dilution lung volumes: which is best for COPD? Chest. 2010;137(5):1108-15.

28. Hurtado A, Fray WW. Studies of Total pulmonary capacity and its subdivisions. lii. Changes with body posture. J Clin Invest. 1933;12(5):825-32. 
29. Rodenstein DO, Stanescu DC. Reassessment of lung volume measurement by helium dilution and by body plethysmography in chronic air-flow obstruction. Am Rev Respir Dis. 1982;126(6):1040-4.

30. Garfield JL, Marchetti N, Gaughan JP, Steiner RM, Criner GJ. Total lung capacity by plethysmography and high-resolution computed tomography in COPD. Int J Chron Obstruct Pulmon Dis. 2012;7:119-26.

31. Tang $Y$, Zhang $M$, Feng $Y$, Liang $B$. The measurement of lung volumes using body plethysmography and helium dilution methods in COPD patients: a correlation and diagnosis analysis. Sci Rep. 2016;6:37550.

32. Grillo L, Irving S, Hansell DM, Nair A, Annan B, Ward S, Bilton D, Main E, Davies J, Bush A, et al. The reproducibility and responsiveness of the lung clearance index in bronchiectasis. Eur Respir J. 2015;46(6):1645-53.

33. Bayfield K, Alton E, Irving S, Bush A, Horsley A, Davies J. Simultaneous SF6 and N2 gas multiple breath washout (MBW); understanding the difference between test gases. Eur Respir J. 2016;48(suppl 60). doi:10.1183/13993003. congress-2016.0A285.

34. Jensen R, Stanojevic S, Klingel M, Pizarro ME, Hall GL, Ramsey K, Foong R, Saunders C, Robinson PD, Webster H, et al. A systematic approach to multiple breath nitrogen washout test quality. PLoS One. 2016;11(6):e0157523.

\section{Submit your next manuscript to BioMed Central} and we will help you at every step:

- We accept pre-submission inquiries

- Our selector tool helps you to find the most relevant journal

- We provide round the clock customer support

- Convenient online submission

- Thorough peer review

- Inclusion in PubMed and all major indexing services

- Maximum visibility for your research

Submit your manuscript at www.biomedcentral.com/submit 